\title{
Dioxin emission estimates and reduction options for Central and Eastern Europe
}

\author{
H. Kok ${ }^{1}$, T. Pulles ${ }^{1} \&$ U. Quass ${ }^{2}$ \\ ${ }^{1}$ TNO Built Environment and Geosciences, Apeldoorn, Netherlands \\ ${ }^{2}$ Müller-BBM GmbH, Gelsenkirchen, Germany
}

\begin{abstract}
The project "Dioxin Emissions in Candidate Countries" was commissioned by the European Commission to a consortium lead by TNO and was finished in the beginning of 2005. The project is part of the Commission's response to the Stockholm Convention on Persistent Organic Pollutants (POPs). The emissions have been estimated, using a method that is consistent for all countries in this study and the earlier EU Dioxin Inventory for the 15 "Old" EU Member States. The national inventory in this study has been discussed with national experts from each of the 13 countries. The results of the study show that the emissions of dioxins to air in the "New" EU Member States and the Candidate Countries are most probably comparable to those in the "Old" EU Member States. There is a small chance that the emissions are a factor 4 to 5 higher because of uncertainties in activity rates of dioxin emitting processes and emission per unit of activity. On the basis of the results we conclude that there is no reason to assume that the concentrations of dioxins in the air in the 13 countries are significantly higher than in the 15 "Old" EU Member States. This however does not exclude possible "hot spots", where relatively high concentrations could occur, due to for instance uncontrolled burning of chlorine containing wastes. Special attention must be given to prevent "illegal" activities in the field of waste combustion.
\end{abstract}

Keywords: dioxin emission, emission inventory, Central Europe, Eastern Europe, activity data, emission factors, waste incineration, primary metal industry, cement industry, residential heating, reduction measures. 


\section{Introduction}

Dioxins and furans, more precisely polychlorinated dibenzo-p-dioxins (PCDD) and polychlorinated dibenzofurans (PCDF) have received wide attention both by scientists and by policy makers, developing international conventions and protocols aimed at protecting the environment from the so-called Persistent Organic Pollutants (POPs). Dioxins and furans (PCDD/F) are unintentionally formed in processes where chlorine containing organic material is heated to high temperatures. Such processes are combustion and incineration of wastes and fuels and certain manufacturing processes of chlorinated phenols and solvents, in pulp and paper industry (chlorine bleaching) and in the metallurgical industry.

As a starting point of any policy to decrease the environmental impact by POPs like dioxins and furans, a quantitative overview of the sources is absolutely essential. Dioxin and furan (PCDD/F) emission inventories have been compiled recently for continental scale [1;2], for national scale [3] and for provincial / local scale [4; 5]. For the western European countries ('Old' Member States) a recent $\mathrm{PCDD} / \mathrm{F}$ emission inventory is available [2]. For New EU Member States and Candidate Member Countries this was not the case. This was one of the reasons for the EU to commission the project "Dioxin Emissions in Candidate Countries". The 13 countries in Central and Eastern Europe, participating in this study are: Bulgaria, Cyprus, Czech Republic, Estonia, Hungary, Latvia, Lithuania, Malta, Poland, Romania, Slovak Republic, Slovenia and Turkey.

When the project was commissioned, these countries were referred to as EU Candidate Member Countries. Since June 2004, 10 of these countries are full members of the EU. Bulgaria, Romania and Turkey now are still candidate countries. In this paper we will continue to label these 13 countries as "New" Member States.

In the study the methods were developed to compile consistent and comparable inventories of $\mathrm{PCDD} / \mathrm{F}$ for the 13 individual countries and to compare these with the inventories of the Old Member States.

This paper presents the results together with the differences in dioxin emissions from several industrial and non-industrial sectors in Old and New Member States. Recommendations are given for the reduction of dioxin load in populated areas.

\section{Methods}

A detailed description of the methods and data used in this study is available in the full report [6]. Below we summarise the main issues.

\subsection{Procedure}

The compilation of the dioxin emission inventory for the 13 countries in this study was a stepwise approach, aimed at making optimal use of both available expertise at the partners in the consortium and the knowledge and expertise in the countries. 


\subsection{Algorithm}

The method applied in compiling the air emission inventory is the "top-downapproach", which is generally applied in almost all emission inventories. For each relevant sector and fuel, the emission is calculated by multiplying an activity rate with an appropriate emission factor:

$$
\text { Emissions }_{\text {sector }, \text { fuel }}=\text { Activity }_{\text {sector }, \text { fuel }} \times \text { Emission Factor } r_{\text {sector, fuel }}
$$

Please note that only combustion processes will use the specification of "fuel". The total inventory then is simply the sum of these sector emissions for all sectors and fuels.

$$
\text { Emissions }=\sum_{\text {sectors, fuels }} \text { Emissions }_{\text {sectors, fuel }}
$$

In compiling the emission inventory for a country, for each relevant sector and fuel activity data and appropriate emission factors must be collected.

\subsubsection{Sector and fuel definitions}

Emission inventories in most countries are compiled using a set of sector definitions that has been developed under the work of IPCC to be applied in emission inventories for the Climate Change convention (UNFCCC). Recently, the Convention on Long Range Transboundary Air Pollution (LRTAP) also adopted a set of sector definitions that is fully consistent with these IPCC sector definitions.

\subsubsection{Technologies}

To calculate the emissions for each of the activities in the sectors emission factors are needed. These emission factors depend on the technology that is applied to perform the activity. Any activity could in principle be performed with different technologies in different countries representing the different technologies within one country. This is also reflected in available emission factors like the UNEP Chemicals Toolkit, in many cases differing by a factor of 10 between technologies [7].

\subsubsection{Activity data}

Activity data for the inventory were obtained from a series of publicly available data sources (e.g. IEA, EUROSTAT) and data used in the CEPMEIP-project [8]. Where updated data were provided by national experts, participating in the workshops, these replaced the data in the international data sets.

We assumed the uncertainties in the activity data, based on international statistics as $+/-30 \%$ (95\% confidence interval), except for population sizes, which were assumed to be quite accurate $(+/-1 \%)$. 


\subsubsection{Emission factors}

The majority of emission factors are derived from the UNEP Chemicals Toolkit [7]. A number of countries have provided country specific emission factors based on dioxin emission measurements. If no information was available on the state of reduction technology used in principle we selected the highest one for that activity reflecting the idea that most of the industrial installations in Central and Eastern Europe will have limited abatement techniques.

For some activities (e.g. preservation of wood, cigarette smoking, fires), per capita emission factors were derived from the EU inventory [2].

Wherever the UNEP Chemicals toolkit provides emission factors for different technologies, these different emission factors were interpreted as the uncertainty range for these emission factors.

\section{Results of emission inventory}

\subsection{Dioxin emission of 'new' $E U$ member states}

Taking the uncertainties as described above into account, the national total emissions in each of the 13 countries are estimated as presented in table 1.

Table 1: Estimates for national total emissions to air in the 13 countries in grams for the year 2000 .

\begin{tabular}{|l|r|r|r|}
\hline Country Name & 5 percentile & best estimate & 95 percentile \\
\hline Bulgaria & 70 & 300 & 800 \\
\hline Cyprus & 3 & 7 & 40 \\
\hline Czech Republic & 85 & 320 & 990 \\
\hline Estonia & 3 & 9 & 45 \\
\hline Hungary & 45 & 120 & 450 \\
\hline Latvia & 10 & 18 & 270 \\
\hline Lithuania & 10 & 50 & 200 \\
\hline Malta & 1 & 4 & 13 \\
\hline Poland & 250 & 800 & 1900 \\
\hline Romania & 120 & 500 & 1300 \\
\hline Slovak Republic & 45 & 180 & 500 \\
\hline Slovenia & 10 & 35 & 100 \\
\hline Turkey & 200 & 1000 & 2800 \\
\hline Grand Total & $\mathbf{1 3 0 0}$ & $\mathbf{3 2 0 0}$ & $\mathbf{8 0 0 0}$ \\
\hline
\end{tabular}


For each country, both the value as obtained from the inventory and the lower and upper limits of the $90 \%$ confidence intervals are presented.

The total dioxin emission to air in the thirteen countries is estimated at $3.2 \mathrm{~kg}$ TE per year. The uncertainty range around this value is 1.3 to $8.0 \mathrm{~kg} \mathrm{TE}$ per year (90\% confidence interval).

\subsection{Sector contributions}

Contributions by different sectors to the total emissions are given in Figure 1.

Important sources are in the waste sector and industrial production (metals and minerals). Minor contributions are from product use and fuel combustion. The EU inventory for the "Old" EU member States shows a comparable distribution. Together these sources are responsible for over $60 \%$ of the total dioxin emissions in the studied area.

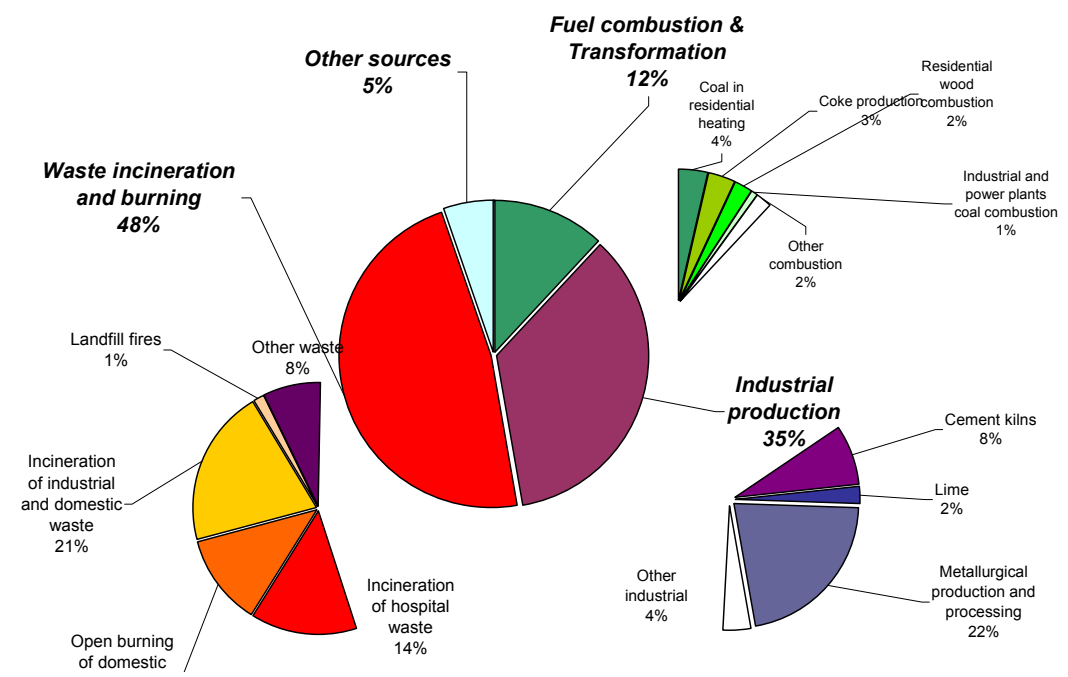

Figure 1: $\quad$ Sector contribution to dioxin emissions to air in the 13 countries.

Major dioxin emission sources occur both in a limited number of larger industrial facilities and in numerous small residential sources (stoves, uncontrolled burning, fires etc.). Our best estimate of the contribution between these two source categories shows that 30 to $40 \%$ of the emissions might arise from the small residential sources. This figure however is highly uncertain.

\subsection{Dioxin concentration in populated areas and their potential health impacts}

About one third of the emissions of dioxins to air are due to non-industrial (area) sources, where low level emission occurs in large numbers of small equipment 
(stoves, cars, open waste burning). These emissions obviously occur in the direct neighbourhood where people live and hence will give rise to elevated concentrations of dioxins in the direct surroundings of where people live. As an example, dioxin concentrations in ambient air of up to $8.000 \mathrm{fg} \mathrm{TE} / \mathrm{m}^{3}$ (which is a factor of 200 above usual background concentrations) have been found in wintertime at Cracow, Poland [9]. Fugitive emissions from industrial activities carried out on industrial premises (e.g. dust resuspension by vehicles, dispersion from heaps) can have an impact on the adjacent areas. A recent screening of POPs concentrations in free-range chicken eggs frequently revealed elevated $\mathrm{PCDD} / \mathrm{F}$ concentrations in the vicinity of industrial areas, proving direct impacts of industrial emissions on the food chain. In the area considered here such incidents were found in Slovakia, Czech Republic, Bulgaria and Turkey.

\section{Reduction of dioxin emission}

\subsection{Emission reduction at waste incineration processes}

Waste incineration comprises the incineration of municipal solid waste (MSW), hazardous waste, medical waste and sewage sludge. In the early 1990s flue gas concentrations of MSW incinerators in Germany were about $10 \mathrm{ng} \mathrm{TE} / \mathrm{m} 3(\mathrm{TE}=$ Toxicity Equivalent) [10]. According to the waste incineration directive incineration plants must comply with an emission limit value of $0.1 \mathrm{ng} \mathrm{TE} / \mathrm{m} 3$ in the exhaust gas [11]. This means an emission reduction of about $99 \%$. This reduction can be achieved by combining three types of measures:

- Pre-incineration measures e.g. removal of chlorinated compounds such as PVC). This however has shown little influence on the resulting concentration.

- Incineration process control to compensate for the natural variability in fuel quantity and the controlling factors that govern the rate of chemical reactions. Solid waste is not a homogeneous material and should be mixed very well before charging it to the furnace.

- Post-combustion control will remove unwanted contaminants from the waste gas stream.

Of these the third is the most important one. The three key aspects of such air pollution control systems are reagent addition, waste gas temperature control and particulate removal. First step in the removal of contaminants from the incinerator gases is the removal of particulates and acids by means of filters and chemical scrubbers. There are different possible additional techniques and their combinations that achieve a $\mathrm{PCDD} / \mathrm{F}$ concentration of smaller than $0.1 \mathrm{ng}$ $\mathrm{TE} / \mathrm{m} 3$ in the cleaned gases. The systems are based on an activated coke bed filter or a flue gas injection system (injection of a mixture of lime and coke before a fabric filter). Annual costs for complete flue gas control systems for achieving all emission limit values (inclusive PCDD/F) stated in the waste 
incineration directive amounts to $€ 50$ to $€ 100$ per ton of domestic waste incinerated.

\subsection{Emission reduction in industry}

\subsubsection{Emission reduction at sinter plants in primary metal industry}

Sintering is the baking of moistened mixtures of small-particle iron ores with coke and lime to form lumps of a size which is suitable for the metallurgical process. In the sintering process dioxins are formed and adsorbed on dust particles in the waste gases from the sinter belt. The reduction measure usually used is dedusting of the exhaust air. The target value for the concentration of dioxin in the dedusted belt exhaust gases $(<0.5 \mathrm{ng} \mathrm{TEQ} / \mathrm{m} 3)$ can only be reached by an additional cleaning device (e.g. a second filtrating filter after cooling and adding an adsorbent like active carbon to the exhaust gases).

\subsubsection{Emission reduction at cement kilns}

Dioxins can be formed in/after the preheater and in the air pollution control device if chlorine and hydrocarbon precursors from the raw materials are available in sufficient quantities. The reformation of dioxins and furans is known to occur by de novo synthesis within the temperature window of cooling from 450 to $200{ }^{\circ} \mathrm{C}$. Thus it is important that as the gases are leaving the kiln system they should be cooled rapidly through this range.

\subsection{Emission reduction at residential heating}

Residential heating in small-scale firing places takes place in the power range up to about $50 \mathrm{~kW}$ for cooking and heating purposes. Solid fuels like coal, coke and wood give relative high emissions of PCDD/F (10-100 ug TE/TJ). Oil fired stoves have a factor 10 lower and gas fired stoves a factor 100 lower emission per TJ energy input compared with solid fueled stoves [10].

Emission reduction can be achieved by reduction of energy demand, fuelrelated measures and firing-place related measures. Reduction of energy demand is achieved by improved thermal insulation of houses. Fuel-related measures aim at the burning of standard dry and clean natural wood. However, in solid fuel firing places in households, illegal co-incineration of waste containing chlorine components and waste wood cannot be ruled out. Co-burning of wastes leads to a dramatic increase in the dioxin emission by solid fuel firing places [13].

According to the differences between the emission factors for solid, liquid and gaseous fuels replacement of solid fired stoves by oil fired stoves or preferably gas fired stoves would reduce the PCDD/F emissions to a great extent in populated areas.

\section{Conclusions}

Based on the inventory built for the 13 'New' EU Member States there is no significant difference in dioxin emissions between the thirteen countries in this study and the fifteen 'Old' EU Member States; hence no specific action to reduce 
dioxin emissions in these countries can be identified for the new EU Member States.

However, uncontrolled burning of domestic waste in backyards or coincineration of waste in small stoves is a practice that should be paid attention to in view of the elevated PCDD/F concentrations in ambient air occasionally found. This would be also important for other reasons than for dioxin emissions (recovery of valuable materials; emissions of other pollutants as POPs, PAH, particulates, black smoke, etc.). The EU has already legislation in place that aims at improving waste management and waste treatment. The Commission could support programs to inform authorities and to educate the public to properly dispose of wastes via waste collection and waste treatment systems, using incineration in modern waste incinerators and land filling in modern well managed and well protected waste disposal sites.

Residential coal and wood combustion in small stoves also might be phased out because of other environmental problems like the emissions of particulates and PAHs. The emissions of dioxins from these sources add to the problems caused by the use of solid fuels for small residential heating systems.

Dioxin emissions from larger (industrial) facilities could be abated by technical measures. Implementation of the relevant EU Directives $[11 ; 12]$ and Best Available Technologies (BAT) as described in the IPPC-BREF documents probably will significantly reduce the dioxin emissions from these larger industrial facilities. It should be monitored, however, if these improvements equally can be found also with respect to fugitive emissions from ground-near sources.

\section{References}

[1] Berdowski, J.J.M., Baas, J., Bloos, J.P.J., Visschedijk, A.J.H., PYJ Zandveld, P.Y.J., The European Emission Inventory of Heavy Metals and Persistent Organic Pollutants for 1990. Forschungsbericht 10402 672/03 des Bundesministers für Umwelt, Naturschutz und Reaktorsicherheit.

[2] Quass, U., Fermann M. and Bröker G., The European Dioxin Air Emission Inventory Project--Final Results. Chemosphere, Volume 54, pp. 1319-1327, 2004.

[3] Kakareka, S.V., Sources of persistent organic pollutants emission on the territory of Belarus, Atmospheric Environment, Vol 36, pp 1407-1419, 2002.

[4] Caserini, S. and Monguzzi, A.M., PCDD/Fs emissions inventory in the Lombardy Region: results and uncertainties, Chemosphere, Volume 48, pp. 779-786, 2002.

[5] Pulles, T., Kok H.J.G. and Pesik J., Dioxin emissions in the Haifa region, TNO report $\mathrm{nr} \mathrm{R}$ 2004/016, TNO Apeldoorn, 2004.

[6] http://www.envihaifa.org.il/heb/dioxins012004.pdf.

[7] Pulles, T., Kok, H.J.G., Quass, U., Juery, C. and Mategovicova J., Dioxin emissions in Candidate Countries. TNO report R\&I-A R 2005/054, 2005. 
[8] Standardized Toolkit for Identification and Quantification of Dioxin and Furan Releases, $1^{\text {st }}$ edition, UNEP Chemicals, Geneva, 2003.

[9] Pulles, T. and Visschedijk A.J.H., Emission estimation methods for particulates: the CEPMEIP emission factor database. http:/www.air.sk/tno/cepmeip $\quad$ http://www.dioksyny.pl/files/Results from measurements Poland 2002 Odense.pdf.

[10] Detzel, A. et al., Investigation of emissions and abatement measures for persistent organic pollutants in the Federal Republic of Germany, Research Report 29544 365, Federal Environmental Agency, Berlin, 1998.

[11] Directive 2000/76/EC of the European Parliament and the Council of 4 December 2000 on the incineration of waste. Official Journal of the European Communities, L 332, pp. 91-111, 2000.

[12] Best Available Techniques Reference Document on the Production of Iron and Steel. IPPC, Dec. 2001. http://eippcb.jrc.es/pages/FActivities.htm.

[13] Launhardt, T., PCDD/F- und PAK-Emissionen aus Holzfeuerungsanlagen für den häuslichen Bereich. Fach-seminar "Dioxin- und Gesamtemissiononsminimierungstechnieken mit Betriebserfahrungen”. VDI-Bildungswerk, 19 - 20 September 1996, München. 